Eur. J. Clin. Chem. Clin. Biochem.

Vol. 31, 1993, pp. 829-837

(C) 1993 Walter de Gruyter \& Co.

Berlin · New York

\title{
Laboratory Assessment of Five Glucose Meters Designed for Self-Monitoring of Blood Glucose Concentration
}

\author{
By Katrien Devreese and G. Leroux-Roels \\ Centraal Laboratorium, Universitair Ziekenhuis Gent, Gent, Belgium
}

(Received February 22/August 30, 1993)

\begin{abstract}
Summary: We describe a laboratory assessment of five blood glucose meters. The instruments' analytical characteristics under optimum laboratory conditions and examination of potential sources of errors were intercompared. All glucometers produced precise results, and in all but one meter the CV values varied between $1.5 \%$ and $6 \%$. CV's for reproducibility and within-day precision of Glucometer Gx were $10.5 \%$ and $7.3 \%$. Sample volume, blood incubation time and colour stability of the strip may influence the results of blood glucose measurements with glucose meters. Underloading the sample strip had statistically significant effects on normal blood glucose values for all meters. One Touch II gave also significantly different results when the strip was overloaded. Incubation times shorter or longer than those recommended by the manufacturer influenced the results of all glucose meters. After colour development of the strip, changes were small for Haemo-Glukotest 20-800R strips and Glucotrix, whereas Accutrend glucose strips had to be read immediately following the prescribed incubation time. Comparison of the glucose meter results with those obtained by the hexokinase method showed good correlation coefficients for Reflolux $S(r=0.992)$, Accutrend $(r=0.988)$, One Touch II $(r=0.942)$, Glucometer $G x(r=0.986)$ and Glucocard $(r=0.976)$. Error grid analysis showed that the results of all meters were clinically correct. Variations in haematocrit are known to be a source of errors when blood glucose is determined with a test strip. In the normoglycaemic range the results obtained with Accutrend and Glucocard were not influenced by even extreme haematocrit values. In the high glucose concentration range there was a decrease in blood glucose values with increasing haematocrit for all meters. This error was smaller with Accutrend and Glucocard than with the other meters.
\end{abstract}

Although the new versions of the monitors are easier to use, their analytical performance is not superior to earlier models.

\section{Introduction}

Self-monitoring of blood glucose concentrations is a common practice in the routine management of diabetic patients (1).

Several devices are now available for monitoring glucose concentration in whole blood. Visually readable strips and reflectance photometers are widely used. While glucose determination by means of visual assessment of the test strips is limited to range-related comparison of developed colour, blood glucose meters are able to display continuous values. The reflectance photometers have undergone extensive modification in the past few years, and "improved versions" of reflectance photometers of several manufacturers are on the market. We assessed the performance of five such instruments:

Reflolux S (Boehringer Mannheim Canada Ltd., Dorval, Quebec),

Accutrend (Boehringer Mannheim Canada Ltd, Dorval, Quebec),

One Touch II (Lifescan Inc., Mountain View, CA 94043),

Glucometer Gx (Ames Division, Miles Laboratories, Etobicoke, Ontario) and 
Glucocard (Menarini Diagnostics, DIC Kyoto, Kagaku Co. Ltd. Japan).

Although an evaluation of these instruments under working conditions (bedside or ambulatory monitoring) is certainly preferable, this is hard to carry out due to logistic (sample volume needed to perform all the experiments) and ethical restraints (numerous punctures, duration of the examination). We chosen, therefore, to examine the instruments under optimum laboratory conditions. The analytical characteristics of five instruments were intercompared and comparison between the results obtained with these five monitors and a laboratory reference method was made as well.

\section{Materials and Methods}

Materials, samples

Blood from one healthy volunteer was used to reach a sample volume large enough to perform all experiments with the five glucose meters and the laboratory reference method on the same specimens and to prepare a series of samples covering the whole concentration range $(2.20 \mathrm{mmol} / 1-28.80 \mathrm{mmol} / \mathrm{l})$.

A $120 \mathrm{ml}$ source specimen was collected in vacutainer tubes containing lithium heparin (Venoject, Terumo Corp., Tokyo, Japan) by venipuncture from one healthy volunteer. Whole heparinised blood was used for analysis on all glucometers. Plasma was used for the laboratory reference method.

To obtain samples in the high glucose concentration range ( $>10.00 \mathrm{mmol} / \mathrm{l}$ ) specimens were supplemented with glucose powder (Dextropurit, N. V. Maasindustrie, Antwerp). After mixing and equilibration for two hours at room temperature, all samples were simultaneously analysed on all the instruments within an interval of $30 \mathrm{~min}$. Samples in the low glucose concentration range $(<3.50 \mathrm{mmol} / \mathrm{l})$ were obtained by letting the source sample wait at room temperature until natural metabolic depletion produced low glucose levels. Afterwards, all samples were analysed within $30 \mathrm{~min}$. Unspiked samples were used for all experiments in the normoglycaemic range. In these cases the interval between sampling prelevation and analysis was kept lower than 30 min to prevent metabolic changes.

All tests and manipulations were performed by a single operator.

\section{Instruments}

\section{We evaluated}

the Reflolux S (Boehringer Mannheim Canada Ltd., Dorval, Quebec),

the Accutrend (Boehringer Mannheim Canada Ltd., Dorval, Quebec),

the One Touch II (Lifescan Inc., Mountain View, CA 94043),

the Glucometer Gx (Ames Division, Miles Laboratories, Etobicoke, Ontario) and

the Glucocard (Menarini Diagnostics, DIC Kyoto, Kagaku Co., Ltd., Japan).

Table 1 summarizes the main characteristics of the instruments.

The monitors with their respective strips were used according to the manufacturer's instructions.

For comparison, we determined glucose concentrations in plasma using the hexokinase method (RA 1000, Technicon Instruments Corp., Tarrytown, New York, Technicon Diagnostics Glucose reagent, product no. T11-1832). This method is the generally accepted reference method for the determination of glucose in body fluids by spectrophotometric analysis (2).

Tab. 1. Main characteristics of the evaluated blood glucose meters

\begin{tabular}{|c|c|c|c|c|c|c|}
\hline & $\begin{array}{l}\text { Measuring } \\
\text { range }\end{array}$ & Calibration & $\begin{array}{l}\text { Reaction } \\
\text { time }\end{array}$ & $\begin{array}{l}\text { Reaction } \\
\text { principle }\end{array}$ & Memory & Strips \\
\hline Accutrend & $1.3-33.3 \mathrm{mmol} / 1$ & $\begin{array}{l}\text { lot-specific } \\
\text { calibration } \\
\text { strip }\end{array}$ & $20 \mathrm{~s}$ & $\begin{array}{l}\text { glucose-oxidase/ } \\
\text { peroxidase }\end{array}$ & 50 results & $\begin{array}{l}\text { non-wiping, } \\
\text { visual reading } \\
\text { restricted }\end{array}$ \\
\hline Reflolux S & $0.6-27 \mathrm{mmol} / \mathrm{l}$ & $\begin{array}{l}\text { lot-specific } \\
\text { calibration } \\
\text { strip }\end{array}$ & $120 s$ & $\begin{array}{l}\text { glucose-oxidase/ } \\
\text { peroxidase }\end{array}$ & 20 results & $\begin{array}{l}\text { dry-blotting, } \\
\text { visual colour } \\
\text { comparison } \\
\text { for all } \\
\text { concentrations }\end{array}$ \\
\hline One Touch II & $0-33.3 \mathrm{mmol} / \mathrm{l}$ & program number & $45 \mathrm{~s}$ & $\begin{array}{l}\text { glucose-oxidase/ } \\
\text { peroxidase }\end{array}$ & $\begin{array}{l}250 \text { results, } \\
\text { in } 9 \text { groups }\end{array}$ & $\begin{array}{l}\text { non-wiping, } \\
\text { no visual } \\
\text { reading }\end{array}$ \\
\hline Glucometer Gx & $1.4-22.2 \mathrm{mmol} / \mathrm{l}$ & program number & $50 \mathrm{~s}$ & $\begin{array}{l}\text { glucose-oxidase/ } \\
\text { peroxidase }\end{array}$ & 10 results & $\begin{array}{l}\text { dry-blotting, } \\
\text { visual colour } \\
\text { comparison } \\
\text { for all } \\
\text { concentrations }\end{array}$ \\
\hline Glucocard & $2.2-27.8 \mathrm{mmol} / \mathrm{l}$ & $\begin{array}{l}\text { lot-specific } \\
\text { calibration } \\
\text { strip }\end{array}$ & $60 \mathrm{~s}$ & $\begin{array}{l}\text { glucose-oxidase/ } \\
\text { ferricyanide, } \\
\text { conductivity } \\
\text { measurement }\end{array}$ & last result & $\begin{array}{l}\text { non-wiping, } \\
\text { no visual } \\
\text { reading }\end{array}$ \\
\hline
\end{tabular}




\section{Quality control materials}

We used the aqueous-based controls

'Reflolux II Control' (Boehringer Mannheim) low and high concentration,

'Accutrend Control' (Boehringer Mannheim) normal and high concentration,

'One Touch Normal Control' (Lifescan Inc.),

'Dextro-check Control' normal, low and high control (Ames Division).

Control solutions for the Glucocard were not available at the time of evaluation.

\section{Data analysis}

The relation between the results obtained with the blood glucose monitors for whole blood and the laboratory method for plasma was calculated by linear regression analysis according to Deming (3). The Pearson rank correlation coefficient was calculated for the corresponding quantities.

The Fisher test was used to determine the significance of observed differences (4).

\section{Evaluation methods}

\section{Precision of the glucose meters}

\section{Reproducibility}

Samples for the low and normal concentration range were the same for all meters; in the high concentration range ( $>13.9$ mmol/l) different samples were used. We determined the precision of each analytical system by repeatedly $(n=10)$ measuring the whole blood glucose concentrations in the normal, low and high concentration ranges.

The coefficient of variation $(\mathrm{CV})$ was calculated for each monitor.

\section{Within-day precision}

Within-day precision was determined by a ten-fold glucose measurement with four of the five glucose monitors, each with its corresponding aqueous glucose control solution. Control solutions for Glucocard were not yet available at the time of evaluation. Aqueous glucose solutions were used instead of blood specimens because of the stability of the former. CV's were calculated for each monitor.

\section{Between-day precision}

Between-day precision for four of the glucose meters (Reflolux S, Accutrend, One Touch II, and Glucometer Gx) was determined by measuring each manufacturer's corresponding aqueous glucose control solution on eight consecutive days. CV's were calculated for each monitor.

Variation in the size of blood sample applied on the test strip

The sample volume required to properly cover the test pad of most strips was $25^{\circ} \mu \mathrm{l}$. For the Glucocard test strips the volume was fixed at $5 \mu$ due to the strip design.

To evaluate the effect of under- and overloading of the strips, the pads were covered with $10,15,25,50,75$ or $100 \mu$ l of whole blood. All samples were taken from a single pool with known glucose content. The strips were incubated with whole heparinised blood with glucose concentrations in the normal, low and high ranges, and read according to the manufacturer's instructions with Reflolux S, Accutrend, One Touch II, Glucometer Gx. As a minimum volume for Reflolux S, One Touch II, Glucometer Gx $10 \mu \mathrm{l}$ was used; Accutrend Glucose strips were insufficiently covered by volumina less than $15 \mu \mathrm{l}$.

The mean and standard deviation (S. D.) of ten consecutive determinations were calculated and the Fisher test was used to determine the significance of the observed differences $(p<0.05)$.

\section{Variation in blood incubation period}

The effect of variation in incubation time was evaluated by incubating the strips for periods shorter than or exceeding the incubation time prescribed by the manufacturer. Following the manufacturer's guidelines the blood was incubated on the test pad for $60 \mathrm{~s}$ (Reflolux S), $20 \mathrm{~s}$ (Accutrend), $30 \mathrm{~s}$ (glucometer $\mathrm{Gx}$ ). It was technically impossible to change the incubation time for the One Touch and Glucocard strips, because countdown is started automatically when blood is applied on the strip which has already been inserted into the instrument. Varying incubation times were evaluated for three glucose concentration ranges. For each apparatus all samples used for variable incubation time were taken from one pool with known glucose concentration.

The mean $(\mathrm{n}=10)$ and S.D. were calculated and the Fischer test was used to determine the significance of the observed differences at a $\mathrm{p}<0.05$ level.

\section{Variation in colour stability}

Variation in colour stability was evaluated by measuring the same glucose strip at time $0,10 \mathrm{~min}, 20 \mathrm{~min}, 30 \mathrm{~min}, 1$ hour, 2 hours, 4 hours, 8 hours, and 24 hours after colour development.

Glucose concentrations in the normal, low and high ranges were used. Strips of the Reflolux S, Accutrend and Glucometer Gx were stored in their usual containers at room temperature. For One Touch II and Glucocard glucose strips it was technically impossible to repeat the reading.

\section{Agreement between methods}

Thirty samples containing normal, low and high blood glucose concentrations in the range of $2.5-16.7 \mathrm{mmol} / 1$ were examined on each of the five glucose meters and compared with the laboratory reference method (hexokinase method performed on RA 1000, Technicon Instruments Corp., Tarrytown, New York). For instrument reasons, whole heparinised blood was used on the glucose meters and plasma was used for the reference method. The correlation of the glucometer results with the reference method was calculated.

\section{Error grid analysis}

The error grid analysis describes the clinical accuracy of selfmonitoring blood glucose systems over the entire range of blood glucose values, taking into account the absolute value of the instrument-generated blood glucose concentration, the absolute value of blood glucose concentration measured by the reference method, the relative difference between these two values and the clinical significance of the difference (5). Percent deviation may be a clinically more useful measurement, but only if there is a consistent percentage difference which is clinically meaningful over the entire range of the data being reported. 
Error grid analysis for the evaluation of the clinical implication of patient-generated blood glucose values distinguishes five zones of varying degrees of accuracy of glucose estimations:

Zone A: glucose values that deviate from the reference method by less than $20 \%$. These values are clinically accurate since they would lead to correct treatment decisions;

Zone $\mathrm{B}$ : values that deviate from the reference method by $>20 \%$ but would lead to benign or no treatment errors;

Zone $\mathrm{C}$ : values that would result in overcorrecting acceptable blood glucose levels. Such treatment might cause the actual blood glucose to fall below $3.9 \mathrm{mmol} / \mathrm{l}(70 \mathrm{mg} / \mathrm{dl})$ or rise above $10 \mathrm{mmol} / \mathrm{l}(180 \mathrm{mg} / \mathrm{dl})$;

Zone D: dangerous failure to detect and treat;

Zone E: erroneous treatment zone.

An error grid analysis of 30 data-sets of each of the five glucose meters compared with the hexokinase method (RA 1000, Technicon Instruments Corp., Tarrytown, New York) was performed.

Influence of haematocrit

on blood glucose measurement

Heparinised venous blood with normal and high glycaemic values was centrifugated $\left(3000 \mathrm{~min}^{-1}, 10 \mathrm{~min}\right)$ and packed cells and plasma were reconstituted at different ratios to obtain six samples with haematocrit levels ranging from $0.15-0.60$. Glucose concentrations were measured in duplicate on the five glucometers.

Haematocrit values were determined by a Coulter Counter (Coulter JT 3 Haematology System, Coulter Elektronics Inc., Luton, England).

\section{Results}

Precision of the glucose meters

\section{Reproducibility}

Reproducibility of glucose determination in the low, normal and high concentration range is shown in table 2 .

Tab. 2. Reproducibility of five glucose meters

\begin{tabular}{lcc}
\hline & $\begin{array}{c}\text { Mean } \\
\text { (mmol/l) }\end{array}$ & $\begin{array}{c}\text { CV } \\
(\%)\end{array}$ \\
\hline Accutrend & 2.9 & 2.8 \\
& 4.7 & 3.6 \\
Reflolux S & 28.8 & 5.2 \\
& 2.5 & 6.0 \\
One Touch II & 4.4 & 5.6 \\
& 19.4 & 2.7 \\
Glucometer Gx & 1.35 & 5.5 \\
& 4.0 & 2.0 \\
Glucocard & 22.0 & 1.5 \\
& 2.2 & 4.6 \\
& 6.4 & 10.5 \\
& 15.1 & 7.8 \\
n & 3.5 & 4.8 \\
& 4.4 & 1.7 \\
& 13.9 & 3.0 \\
\hline \multirow{2}{*}{10} & &
\end{tabular}

CV are between 2 and $6 \%$, except for the Glucometer $\mathrm{Gx}$, where the $\mathrm{CV}$ in the normal range is $10.5 \%$ and in the high concentration range $7.8 \%$.

\section{Within-day precision}

In the normal concentration range the lowest $\mathrm{CV}$ $(1.6 \%)$ is seen for One Touch II; Glucometer Gx has a CV of $7.3 \%$. The other results are shown in table 3 .

Tab. 3. Within-day precision with aqueous control solutions

\begin{tabular}{lcr}
\hline & $\begin{array}{l}\text { Mean } \\
(\mathrm{mmol} / \mathrm{l})\end{array}$ & $\begin{array}{c}\mathrm{CV} \\
(\%)\end{array}$ \\
\hline Accutrend & & \\
$\quad$ Control 1 & 3.4 & 2.2 \\
Control 2 & 9.8 & 2.7 \\
Reflolux S & & \\
$\quad$ Control 1 & 2.7 & 5.6 \\
Control 2 & 15.8 & 5.8 \\
One Touch II & & \\
$\quad$ Normal Control & 5.9 & 1.6 \\
Glucometer Gx & & \\
$\quad$ Normal Control & 5.4 & 7.3 \\
$\quad$ Low Control & 2.4 & 9.5 \\
$\quad$ High Control & 13.0 & \\
\hline
\end{tabular}

$\mathrm{n}=10$

\section{Between-day precision}

As shown in table 4, CV's for between-day precision ranged from $3.6 \%$ to $9.9 \%$.

Tab. 4. Between-day precision with aqueous control solutions

\begin{tabular}{lll}
\hline & $\begin{array}{l}\text { Mean } \\
(\mathrm{mmol} / \mathrm{l})\end{array}$ & $\begin{array}{l}\mathrm{CV} \\
(\%)\end{array}$ \\
\hline $\begin{array}{l}\text { Accutrend } \\
\text { control 1 }\end{array}$ & 3.4 & 5.0 \\
$\begin{array}{l}\text { Reflolux S } \\
\text { Control 1 }\end{array}$ & 2.6 & 3.6 \\
$\begin{array}{l}\text { One Touch II } \\
\text { Normal Control }\end{array}$ & 5.9 & 4.0 \\
$\begin{array}{l}\text { Glucometer Gx } \\
\text { Normal Control }\end{array}$ & 4.8 & 9.9 \\
\hline
\end{tabular}

$\mathrm{n}=8$

Variation in the size of the blood sample applied on the strip

Underloading had a statistically significant effect on blood glucose concentrations for Accutrend (normal, low, and high concentration ranges), Reflolux $S$ (normal and high concentration ranges), One Touch II (normal concentration range) and Glucometer Gx (low concentration range). 


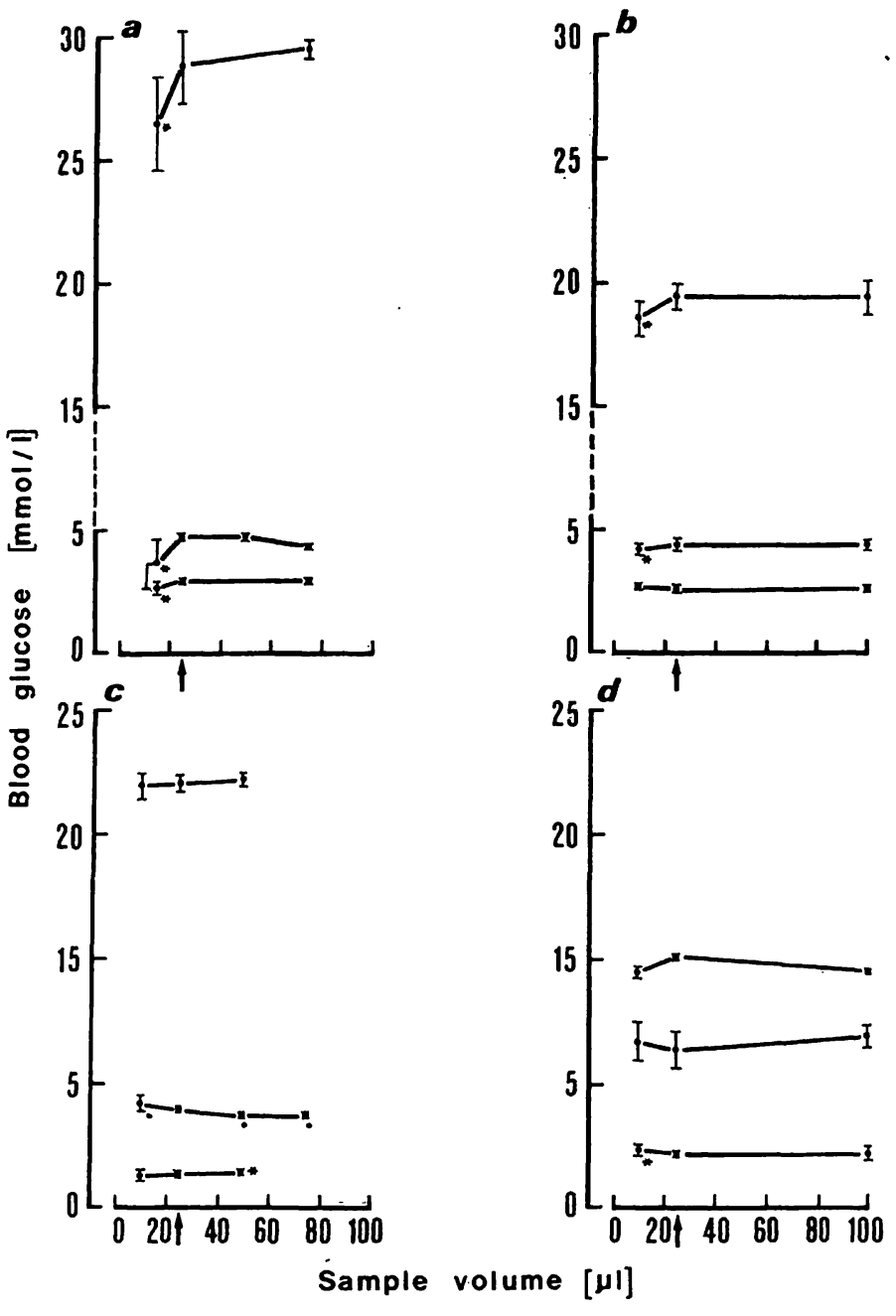

Fig. $1 \mathrm{a}-\mathrm{d}$. Influence of variations in the size of blood sample on the glucose measurements. a: Accutrend, b: Reflolux S,

c: One Touch II, d: Glucometer Gx.

The arrow indicates the usual blood volume $(25 \mu \mathrm{l})$ Error bars indicate \pm S. D. $(n=10)$.

Asterisks indicate results that differed significantly ( $p<0.05$, Fisher test) from those obtained at the appropriate (arrowed) blood volumes.

Overloading the strip had a statistically significant effect for One Touch II in the normal and low concentration ranges (see fig. $1 a-d$ ).
Variation in blood incubation period

Incubation the test strips with blood for periods shorter than those recommended had a statistically significant effect on blood glucose concentrations for all meters (see fig. $2 a-c$ ).

Incubating the Accutrend Glucose strips $40 \mathrm{~s}$ longer than recommended had no statistically significant effect for the low and normal glucose concentration ranges, but gave significant differences in the high glucose concentration range. Incubating the HaemoGlukotest 20-800 R strips (Reflolux S) for periods two or two-and-a-half times as long as the prescribed incubation time induced significantly $(p<0.05)$ different results. Incubating the Glucostix (Glucometer $\mathrm{Gx}$ ) longer than the recommended incubation time also produced significantly different results. Extending the incubation time of the Glucostix for five seconds already induced significantly different results in the high concentration range. Longer incubation made the strip technically unreadable because of the very dark colour development.

\section{Variation in colour development}

Variation in colour development is represented in table 5. After colour development of the strip, we noted further changes in measured blood glucose concentrations during the following half-hour. The changes were small for Reflolux $S$ and Glucometer Gx. However, during the four hours following colour development the blood glucose concentrations measured by Accutrend were very unstable, and changes up to $205 \%$ were noted in the normoglycaemic range.

\section{Agreement between methods}

Comparison of the glucose meter results and those obtained with the hexokinase method are shown in table 6 . The slope of the regression line approached

Tab. 5. Effect of storage on strip colour

\begin{tabular}{|c|c|c|c|c|c|c|c|c|c|}
\hline \multirow{2}{*}{$\begin{array}{l}\text { Time after reading } \\
(\mathrm{min})\end{array}$} & \multicolumn{3}{|c|}{ Accutrend } & \multicolumn{3}{|c|}{ Reflolux S } & \multicolumn{3}{|c|}{ Glucometer Gx } \\
\hline & $\mathrm{N}^{*}$ & $\mathrm{~L}$ & $\mathrm{H}$ & $\mathrm{N}$ & $\mathrm{L}$ & $\mathrm{H}$ & $N$ & $\mathrm{~L}$ & $\mathrm{H}$ \\
\hline $0 * *$ & 100 & 100 & 100 & 100 & 100 & 100 & 100 & 100 & 100 \\
\hline 10 & 179 & 186 & 120 & 106 & 105 & 112 & 79 & 72 & 105 \\
\hline 20 & 195 & 248 & 123 & 108 & 105 & 111 & 77 & 71 & 109 \\
\hline 30 & 205 & 270 & 123 & 108 & 105 & 110 & 75 & 69 & 111 \\
\hline 60 & 194 & 302 & 105 & 107 & 107 & 110 & 76 & 65 & 103 \\
\hline 120 & 164 & 282 & 86 & 107 & 103 & 109 & 73 & 65 & 100 \\
\hline 240 & 91 & 151 & 40 & 106 & 102 & 108 & 64 & 60 & 98 \\
\hline 480 & 89 & 146 & 33 & 106 & 102 & 107 & 65 & 59 & 98 \\
\hline 1440 & 87 & 142 & 36 & 105 & 103 & 104 & 61 & 57 & 94 \\
\hline
\end{tabular}

* N, L, H: samples with normal $(\mathrm{N})$, low $(\mathrm{L})$ and high $(\mathrm{H})$ glucosc concentrations were used.

** glucose concentration at time $0=100 \%$ 

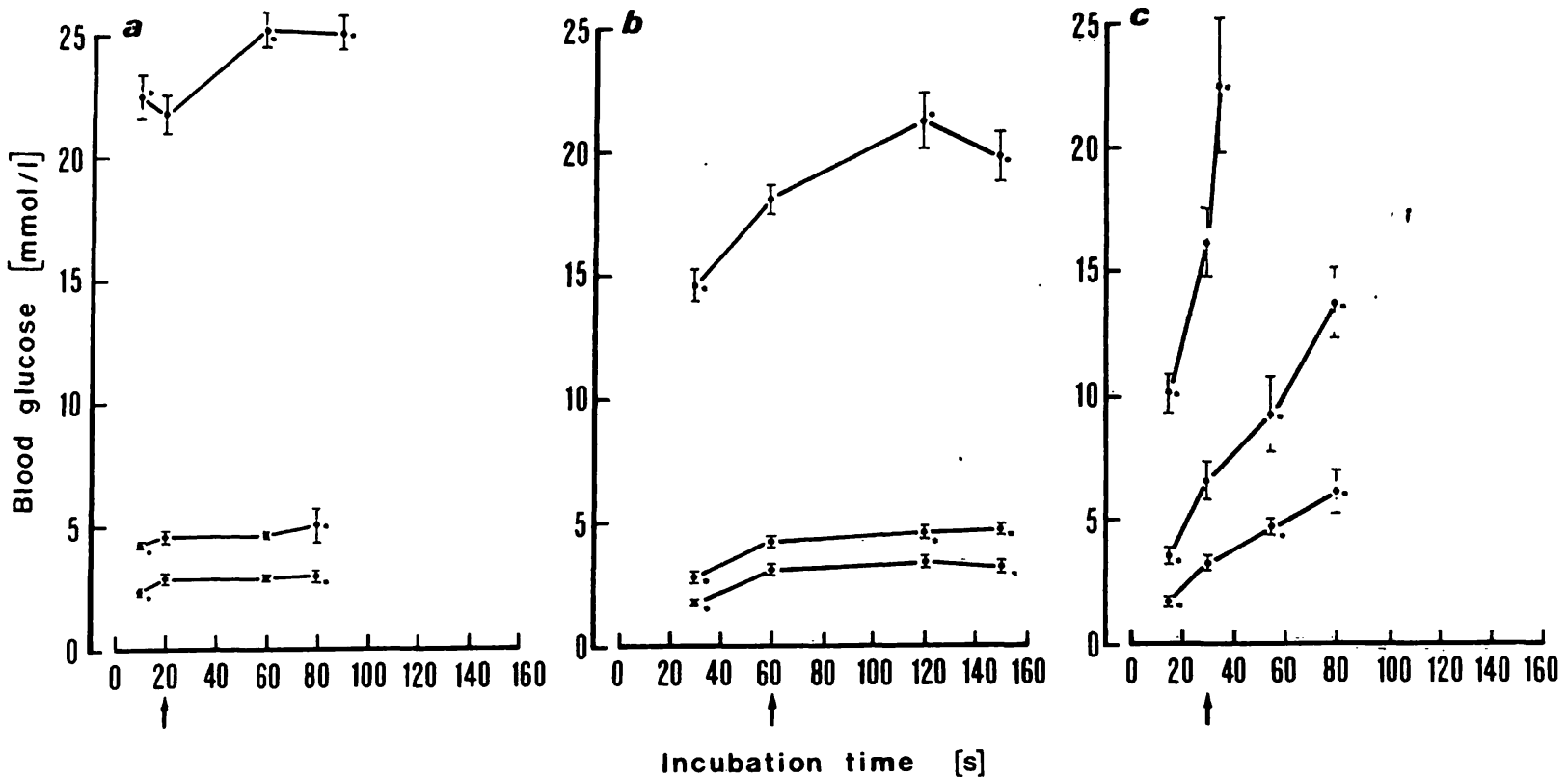

Fig. $2 a-c$. Influence of variations in blood incubation time on glucose measurements. a: Accutrend, b: Reflolux S, c: Glucometer Gx.

The arrow indicates the usual incubation time. Error bars indicate $\pm S$. $D$. $(n=10)$.

Asterisks indicate results that differed significantly $(\mathrm{p}<0.05$, Fischer test) from those obtained using the appropriate incubation time.
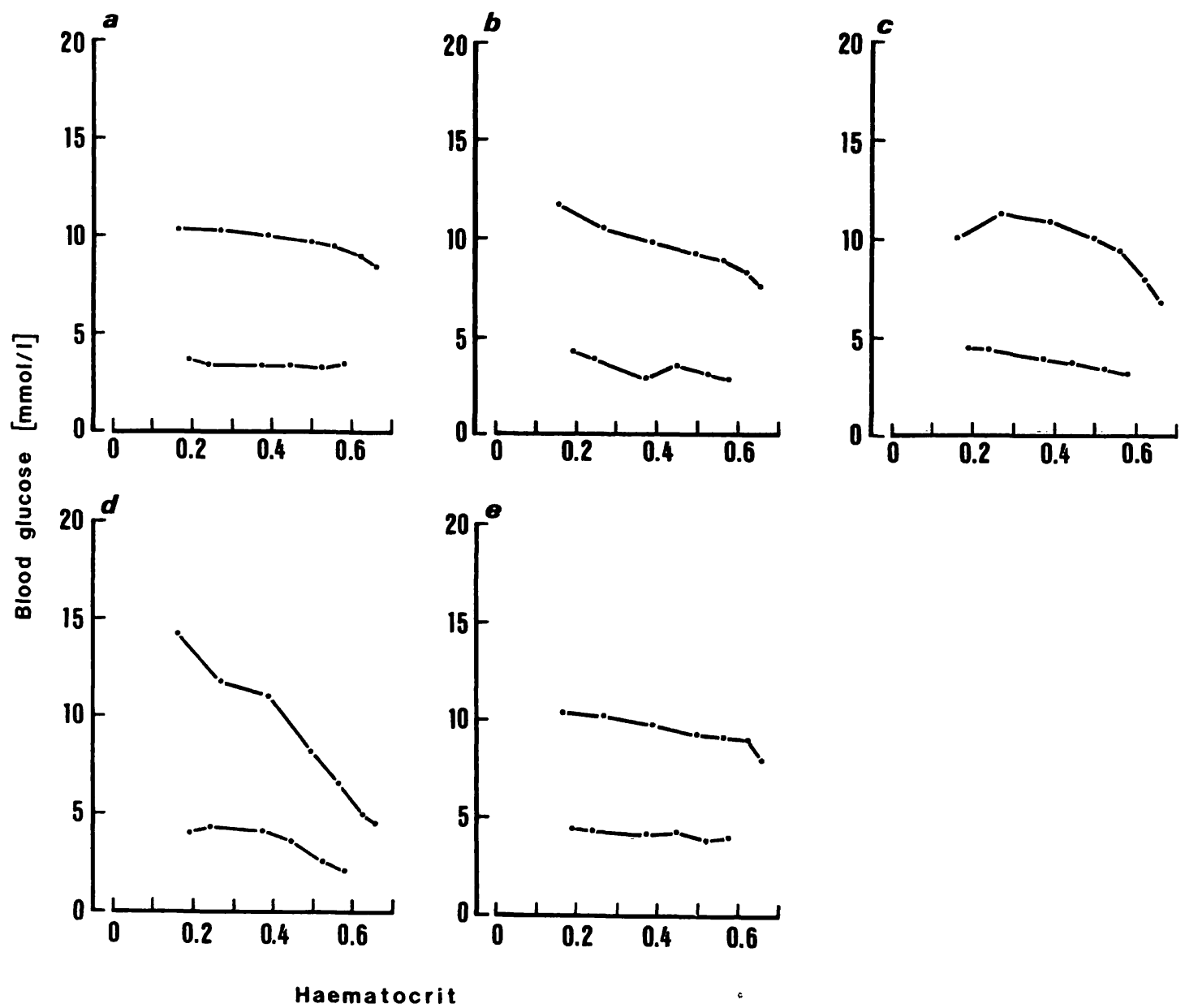

Fig. 3a-e. Influence of variations of haematocrit values on glucose measurements. a: Accutrend, b: Reflolux S, c: One Touch II, d: Glucometer Gx, e: Glucocard. 
Tab. 6. Comparison of glucose meters and hexokinase-method

\begin{tabular}{|c|c|c|c|c|}
\hline & \multirow{2}{*}{$\begin{array}{l}\begin{array}{l}\text { Correlation } \\
\text { coefficient }\end{array} \\
\mathrm{r}\end{array}$} & \multicolumn{3}{|c|}{$\begin{array}{l}\text { Regression analysis } \\
y=a x+b^{*}\end{array}$} \\
\hline & & a & b & $S_{x y} * *$ \\
\hline Accutrend & 0.988 & 0.839 & 0.203 & 0.453 \\
\hline Reflolux S & 0.992 & 1.132 & -1.085 & 0.374 \\
\hline One Touch II & 0.942 & 0.907 & 0.084 & 0.830 \\
\hline Glucometer Gx & 0.986 & 1.047 & -0.576 & 0.453 \\
\hline Glucocard & 0.976 & 1.184 & -1.038 & 0.687 \\
\hline
\end{tabular}

* Linear regression of $y$ (glucometer) $=\mathrm{ax}$ (hexokinasemethod) $+b$

** Standard error of $y$ estimated

$\mathrm{n}=30$

1.0 in three of the five glucometers. For Accutrend the slope was 0.839 , for Glucocard the slope was 1.184 .

\section{Error grid analysis}

Error grid analysis results show that all five instruments generated clinically correct (zone A and B) glucose values. All Accutrend, Reflolux $S$ and One Touch II glucose values are situated in zone A, 8 out of the $30(26.7 \%)$ results of Glucometer $G x$ and 2 out of $30(6.7 \%)$ of the Glucocard are situated in zone $\mathrm{B}$.

Influence of haematocrit on blood glucose measurement

The influence of haematocrit values on blood glucose concentrations is depicted in figure $3 a-e$.

The change in blood glucose concentrations induced by variations in the haematocrit was less than $10 \%$ for measurements performed with Accutrend and Glucocard in the normoglycaemic range. For Reflolux $S$ in the normoglycaemic range an increase of $45 \%$ in blood glucose concentration was noted for decreasing haematocrit values. For One Touch II and Glucometer Gx a decrease of $40-60 \%$ in blood glucose concentration is noted on increasing haematocrit.

In the high glucose concentration range there is for all meters, a decrease in blood glucose concentration on increasing haematocrit values, but the effect was small for Accutrend and Glucocard. The Glucometer $G \mathrm{x}$ was most sensitive to increased haematocrit values.

\section{Discussion}

For this evaluation of 5 glucose meters designed for the self-monitoring of blood glucose concentrations, we have used whole heparinised blood from a single healthy donor for ethical and practical reasons mainly; further, we wished to reduce biological variability as much as possible and we hoped to eliminate the influence of haematocrit in the measurement of glucose concentration. Anticoagulants can affect the measurements of self-monitoring blood glucose meters. Whereas major influences have been described for fluoride-oxalate, the interference of heparin seems to be small (6).

Our evaluation shows that the newer glucose meters are easier to use, but that their analytical performance is not significantly better than that of their predecessors $(7-9)$. Because the primary concern in diabetes control is the detection of changes in blood glucose concentration over time, methods for the self-monitoring of blood glucose concentration should have small CV's (10). The five glucose meters tested produced precise results as demonstrated by $C V$ values between 1.5 and 6.0. The CV's of Glucometer Gx are higher than those of the other four instruments. Glucometer II, the predecessor of Glucometer Gx, displayed similar characteristics $(10,11)$.

To evaluate the reproducibility in the normoglycaemic concentration range, the same whole blood sample was used for all meters. The CV found for Glucometer Gx was $10 \%$, and the glucose value measured with the Glucometer Gx was about $30 \%$ higher than that measured with the other instruments. Consequently, the value obtained with this instrument reached the critical glucose concentration for glycaemia control in diabetic patients. Similar results have been described for the Glucometer II (12).

We also found that aqueous calibration solutions intended for one strip system cannot be used for another. This may be due to the presence in these solutions of stabilisers or preservatives that interfere with the detection reaction on the strip.

Variables such as sample volume, blood incubation time and colour stability of the strip may seriously influence the blood glucose concentration was measured with the monitors (13).

Sample volume is an important variable, since blood loss through a fingerstick wound is unpredictable and may or may not be sufficient for the planned measurement. Glucocard only needs $5 \mu$ l blood to start measuring, which makes the instrument very practical for monitoring, especially of children.

Underloading the strip had statistically significant effects on the measurement of normal blood glucose concentrations for all meters. Only for results of the One Touch strips were significant differences found between normal blood sample volume $(25 \mu \mathrm{l})$ and 
overloaded glucose strips in the normal and low concentration ranges. Problems with sample volume cannot occur with Glucocard, because the required blood volume is fixed at $5 \mu \mathrm{l}$ according to the strip design.

Blood incubation time is critical, but with the most recently developed glucose meters (Accutrend, One Touch II, Glucocard) variations in incubation time have become almost impossible.

After the colour of the strip developed, we noted only small changes for Haemo-Glukotest 20-800R strips and Glucostix, while colour development of the Accutrend Glucose strips was stable for less than 10 minutes. The Accutrend Glucose strips should, therefore, be read immediately after the prescribed incubation time.

An additional advantage of Haemo-Glukotest 20$800 \mathrm{R}$ strips and Glucostix is that it is possible to assess the blood glucose value simultaneously by visual colour comparison over the entire range of measurement by the meter.

Comparison of blood glucose measurements obtained by the glucose meters with those measured by the laboratory reference method, showed a very good correlation. Good correlation coefficients between the data sets do not permit evaluation of the clinical accuracy of the data. Therefore, error grid analysis, based on treatment goals, was performed to evaluate the usefulness and clinical accuracy of the glucose meters $(5,14)$. Our results show that all five glucose meters produce clinically acceptable results.

There are several potential sources of errors when blood glucose is determined with a test strip; even when the technique is performed correctly there are still factors that may induce errors. One of these is the haematocrit value. An important group of subjects with low haematocrit values are diabetic patients with end-stage renal failure (15). The influence of haematocrit is also important in pediatric monitoring.

Previous studies have demonstrated that glucose concentrations measured with strips overestimate the true blood glucose concentration in diabetic patients with low haematocrit, to an extent that may be clinically significant $(15,16)$. This may be due to an accelerated and increased diffusion of plasma to the reagent pad in a specimen with a reduced number of erythrocytes. In the normoglycaemic range the results obtained with Accutrend and Glucocard are not influenced by even extreme haematocrit values. For Reflolux $S$ in the normoglycaemic range an increase in blood glucose concentration is noted for decreasing haematocrit values. For One Touch II and Glucometer Gx an obvious decrease in blood glucose concentration is noted for increasing haematocrit.

In the high glucose concentration range there is a decrease in blood glucose concentration for increasing haematocrit values for all meters, but the effect is small for Accutrend and Glucocard. The results of Glucometer Gx were most influenced by high haematocrit values.

In contrast to home-monitoring or the hospital bedside glucose analysis, our evaluation of the instruments was performed under optimal, privileged working conditions. The tests were performed by a single operator trained in the manipulation of analytical equipment in general and on the test equipment in particular. Tests were performed in one room with a constant ambient temperature. Daily quality controls were performed and pipettes were used to control sample volumes and application conditions.

Excellent performance of an instrument in the hands of trained laboratory personnel is no guaranty for a similar performance when the instruments used outside the laboratory by less well trained or untrained operators $(7,10,17,18)$.

Each of the monitors was easy to use and had clear instructions supplied by the manufacturer. Chances for manipulation errors are minimal with One Touch II and Glucocard (12). Systems where wiping off the blood drop is not necessary, such as Accutrend, One Touch II and Glucocard, are more practical and less time-consuming.

The user-friendliness, cost, and variables involved in the technique - such as sample volume, incubation time, use of test strips, and blotting the strip-should be considered in the choice of an instrument. According to our results one may be confident that Reflolux S, Accutrend, One Touch II and Glucocard will provide sufficient accuracy for routine use outside the laboratory when motivated users, patients and nurses are properly trained and perform all manipulations with care.

\section{Acknowledgement}

We wish to express our gratitude to Boehringer Mannheim, Lifescan Inc., Miles Laboratories and Menarini Diagnostics who provided us with instruments and reagents and to $M$. De Buyzere for critical reading of the manuscript. 


\section{References}

1. Walford, S. \& Alberti, K. G. M. M. (1985) Biochemical self-monitoring: Promise, practice and problems. In: Clinical Biochemistry Nearer the Patient (Marks, V. \& Alberti, K. G. M. M., eds.) Edinburgh: Churchill Livingstone, pp. $200-213$.

2. Caraway, W. T. \& Watts, N. B. (1987) Carbohydrates. In: Fundamentals of Clinical Chemistry, third edition. Tietz, N. W., ed., W. B. Saunders Company, pp. 427-428.

3. Deming, W. E. (1943) Statistical Adjustment of Data. John Wiley and Sons, New York, p. 184.

4. Sokal, R. R. \& Rohlf, F. J. (1981) Biometry: The Principles and Practice of Statistics in Biological Research, 2nd ed. San Francisco, W. H. Freeman, pp. 128-207.

5. Clarke, W. L., Cox, D., Gonder-Frederick, L. A., Carter, W. \& Pohl, S. L. (1991) Evaluating clinical accuracy of systems for self-monitoring of blood glucose. Diabetes Care $10,622-628$

6. Lui, K. F., Ng, W. Y. \& Thai, A. C. (1990) An amperometric measurement, the ExaTech pen meter. Ann. Acad. Med. Singapore 19, 473-476.

7. Begley, J. P. \& Forrest, A. R. W. (1988) Laboratory assessment of three reflectance meters designed for self monitoring of blood glucose concentrations. J. Clin. Pathol. 41, $397-402$.

8. Brooks, K. E., Rawal, N. \& Henderson, R. A. (1986) Laboratory assessment of three new monitors of blood glucose: Accuchek II, Glucometer II and Glucoscan 3000. Clin. Chem. 32, 2195-2200.

9. Koschinsky, T. (1987) Reflolux II, a new blood glucose meter with extended range of measurement. Lab. Med. 11, 97-101.

10. Tate, P. F., Clement, C. A. \& Walters, J. E. (1992) Accuracy of home blood glucose monitors. Diabetes Care 15, 536538.
11. Schier, G. M., Moses, R. G., Gan, I. E. \& Blair, Sc. (1988) An evaluation and comparison of Reflolux II and Glucometer II, two new portable reflectance meters for capillary blood determination. Diabetes Res. Clin. Pract. 4, 177181.

12. Serrano, L., Ackerman, L. \& English, D. (1993) An evaluation of three glucose monitoring systems. Clinical Chemistry News $19,29-30$.

13. Rasaiah, B. (1985) Self-monitoring of the blood glucose levels: Potential sources of inaccuracy. Can. Med. Assoc. J. 132, 1357-1361.

14. Koschinsky, T., Dannehl, K. \& Gries, F. A. (1988) New approach to technical and clinical evaluation of devices for self-monitoring of blood glucose. Diabetes Care 11, 619629.

15. Clark, J. D. A., Goldberg, L., Jones, K. \& Hartog, M. (1991) Are blood glucose reagent strips reliable in renal failure? Diabetic Medicine 8, 168-171.

16. Schlebusch, H., Sorger, M., Voll, A. \& Paffenholz, I. (1991) Netzunabhängige Kleingeräte zur Blutzuckerbestimmung im Krankenhaus - Präzision, Richtigkeit, Hämatokritund Temperatureinfluß. Lab. Med. 15, 535-540.

17. Drucker, R. F., Williams, D. R. \& Price, C. P. (1983) Quality assessment of blood glucose monitors in use outside the hospital laboratory. J. Clin. Pathol. 36, 948-953.

18. Lawrence, P. A., Dowe, M. C., Perry, E. K., Strong, S. \& Samsa, G. P. (1989) Accuracy of nurses in performing capillary blood glucose monitoring. Diabetes Care 12, $298-301$.

Dr. K. Devreese

University Hospital Ghent

Centraal Laboratorium, Blok BII

De Pintelaan 185

B-9000 Gent

Belgium 
